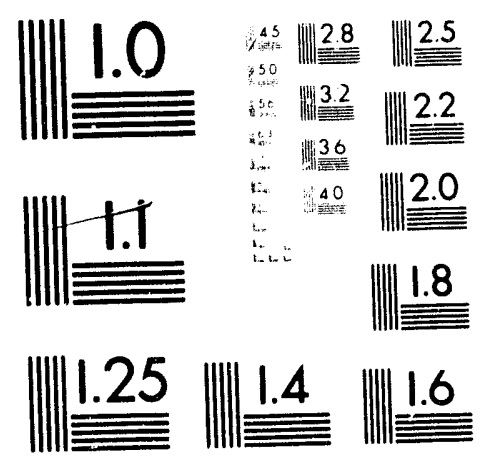



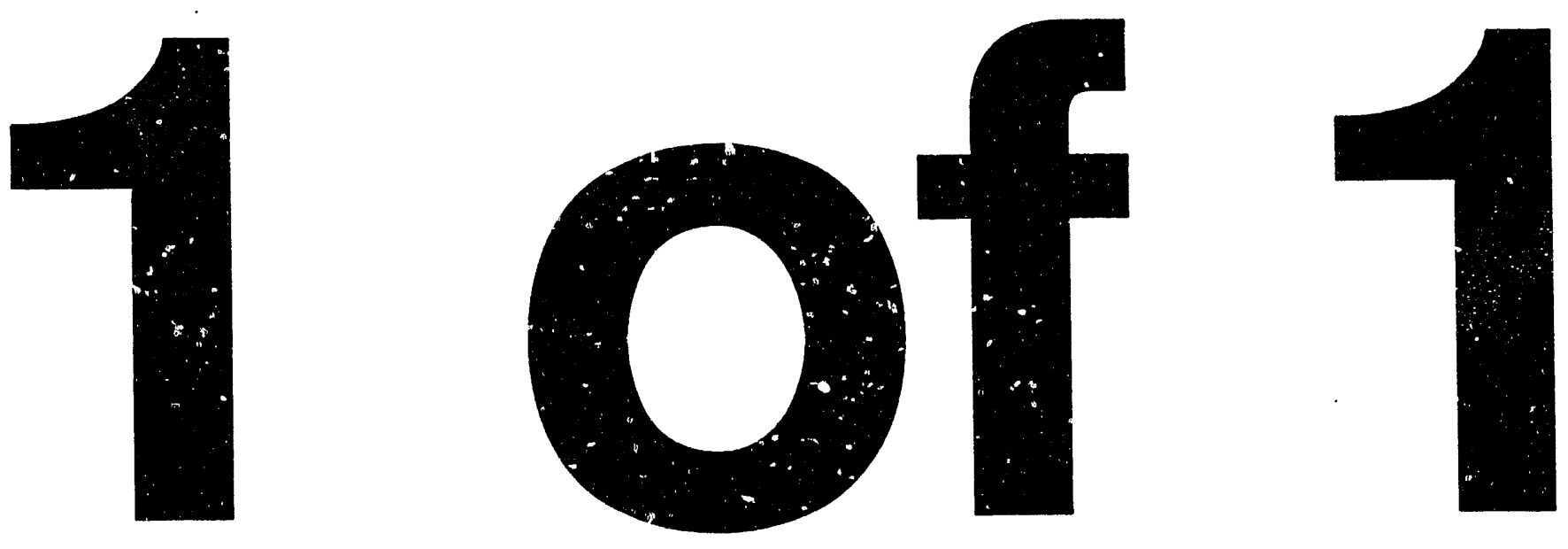


\section{COMRENTS ON NEW TECHNICAL AND ECONOMIC DATA AVAILABLE FOR EPA'S PROPOSED OFFSHORE OIL AND GAS DISCHARGE GUIDELINES AND STANDARDS}

\section{A. INTRODUCTION}

The purpose of this paper is to provide comments on the Envirormental Protection Agency (EPA) Notice in the Federal Register entitled, "Oil and Gas Extraction Point Source Category, Offshore Subcategory; Effluent Limitations Guidelines and New Source Performance Standards; New Information and Request for Comments" (53 FR 41356; 0ct. 21, 1988). This Notice announces the availability of new technical, economic and environmental assessment information relating to the development of Best Available Technology economically achievable (BAT) and New Source Performance Standards (NSPS) regulations under the Clean Water Act governing the discharge of drilling fluids (muds) and drill cuttings from offshore oil and gas facilities. The Notice is part of a ruiemaking process which formally began with the initial release of rules in August 1985 and which incorporates numerous comments and additional data received subsequent to the release of the 1985 rules.

These comments are based on a review of the Notice and of several publicly available background documents which concentrate on the econouic and energy impacts of the proposed rules. The primary background document reviewed was a contractor report entitled "Economic Impact Analysis of Effluent Limitations Guidelines and Standards for the Notice of Data Availability for Drilling Fluids and Drill Cuttings for the offshore $0 i l$ and Gas Industry". In this document, the economic impacts of alternative regulatory scenarios proposed in the Notice were analyzed. This report was prepared by the Eastern Research Group. Inc. (ERG) for EPA, and was completed in October, 1988.

\section{DISCLAIMER}

This report was prepared as an account of work sponsored by an agency of the United States Government. Neither the United States Government nor any agency thereof, nor any of their employees, makes any warranty, express or implied, or assumes any legal liability or responsibility for the accuracy, completeness, or usefulness of any information, apparatus, product, or process disclosed, or represents that its use would not infringe privately owned rights. Reference herein to any specific commercial product, process, or service by trade name, trademark, manufacturer, or atherwise does not necessarily constitute or imply its endorsement, recommendation, or favoring by the United States Government or any agency thereof. The views and opinions of authors expressed herein do not necessarily state or reflect those of the United States Government or any agency thereof. 
The comments in this paper will concentrate on the following five issues:

- Estimated proj ct impacts are misrepresented by assuming weighted-average incremental costs of regulation.

Economic impacts are inaccurate, since annual compliance costs will likely affect the number of wells drilled. by the effect of compliance costs on project economics and the reduction in industry cash flows on capital available for drilling.

- Initial well productivity assumptions for various scenarios do not vary with field size.

- The assumed lease costs, which are based on historical data, do not accurately reflect the future value of leases.

- The exponential decline rates assumed for the Pacific are too high.

Each of these issues are discussed in more detail in this paper.

\section{B. BACKGROUND}

The Federal Register Notice pertains to the development of proposed BAI and NSPS regulations governing the discharge of drilling fluids and cuttings from offshore facilities and the assessment of economic impacts associated with these proposed regulations. The final regulations will probably consist of the following regulatory components:

\footnotetext{
- No discharge of oil-based drilling fluids or cuttings associatad with such fluids

- No discharge of diesel oil in detectable amounts

- No discharge of "free oil" as measured by the static sheen test
} 
- Toxicity limitations as measured by a 96-hour LC-50 test

- Limitations on mercury and cadmium concentrations in drilling fluids.

The economic impact analysis performed by ERG for EPA consisted cf several steps. First, a set of 33 model projects, which were intended to account for the diversity of situations existing in the offshore, were specified. Second, projections of future industry activity (independent of the proposed regulations) were formulated for the 1986-2000 time period, based on forecasts provided by the Minerals Management Service (MMS). Third, annual regulatory compliance costs were estimated by: the Industrial Technology Division of EPA, assuming four potential regulatory approaches. These compliance costs were based on estimated toxicity failure rates associated with the use of water-based drilling muds. Fourth, the regulatory impact of the model projects was determined for each of the regulatory approaches. In this assessment, weightedaverage compliance costs per well used in the evaluation of the model projects were determined by dividing the total annual compliance costs by the estimated average number of wells drilled per year for a particular region. Finally, based on the estimated compliance costs, the impacts on the oil and gas industry, federal and state revenues, and the federal balance of payments were estimated.

\section{COMENTS}

The comments in the paper will focus on assumptions and procedures leading to the economic and energy impact assessments performed for EPA. Each of the major issues requiring comment are discussed in the paragraphs below. 
Inaccurate Representation of Eroject-Level Regulatory Impacts.

In the economic impact assessment presented in the ERG report, the economic impacts of the various regulatory approaches on representative projects were determined assuming the weighted-average cost per well for each approach. This methodology fails to account for the specific impact on projects using water-based drilling fluids which fail toxicity or oil content limitations, and may tend to misrepresent the true energy and economic impacts of the regulations. Many operators will be unable to establish, a priori, whether the drilling fluids they use will fail the toxicity or static sheen test. As a result, the economic justification of their project will assume that offshore discharge is prohibited (as a wort case), and projects which appear to be marginal or uneconomic will not be pursued, even though offshore discharge was possible in their situation.

\section{Effect of the Regulations on Levels of Offshore Drilling.}

In the ERG assessment of regulatory compliance costs, it was assumed that, 978 wells per year would be drilled in the offshore, based on MMS projections. The allocation of these wells among the various regions was based on historical development trends.

The MMS projections, however, assumed no incremental compliance costs were imposed on the offshore industry. The increased costs associated with the proposed regulations will probably result in fewer wells drilled in the offshore. Some projects that would have been economic would become uneconomic under the burden of the increased regulatory requirements. In addition, the added regulatory costs could decrease the net cash flow available to the industry, making less cash available for drilling. Therefore, the imposition of the regulations would result in fewer offshore wells drilled. This will result in apparenty lower compliance costs, but greater impacts in terms of potentia: offshore resource development and production. 


\section{Accounting for Well Productivity as a Function of Field Size.}

A number of experts have documented that oil and gas well productivity, and thus peak production rates, of wells in the Gulf of Mexico and elsewhere are a function of field size. ${ }^{1}$ The number of wells required to develop an offshore field, and consequently, the number of platform slots required, are dependent on the size of the field. Therefore, it is reasonable to assume that wells on smaller platforms will have lower peak production rates, on average, than wells on larger platforms. In the ERG report, all wells in a particular region were assumed to have the same peak production rate.

Past work by ICF-Lewin Energy.has resulted in the establishment of tables relating oil field size to average well productivity for the Gulf of Mexico, Pacific, and Atlantic offshore regions. ${ }^{2}$ Table 1 shows the estimated well productivity associated with ERG's assumption for peak production rates for the region. Also shown is the field size that would correspond to that well productivity, based on the ICF-Lewin field size/well productivity relationships, and the number of slots that would correspond to a platform developing an oil field of that size.

The effect of assuming that well productivity is independent of field size is that the economic evaluation of small fields (those with fewer slots than that indicated for each region in Table 1) will be overstated, while understating the economic attractiveness of the larger fields (platforms with a greater number of slots). This will have the greatest impact in the shallow water ar?as of the Gulf of Mexico, where the majority of future new field

1 for example, see Attenasi, E.D. and Haynes, J., "Future Supply of $0 i 1$ and Gas from the Gulf of Mexico," USGS Paper 1294, Washington, D.C. (1983); U.S. Department of Interior and U.S. Department of Energy, "Future Supply of $O$ il and Gas from the Permian Basin of West Texas and Southeastern New Mexico", U.S. Geological Survey Circular 828, Washington, D.C. (1980); and Kuuskraa, V.A., Ryan, P, and Muller, J.M., "Economics of Offshore Oil Production," Society of Petroleum Engineers Paper No. 6351 (1977)

${ }^{2}$ ICF-Lewin Energy, A Model for the Economic Analysis of U.S. Undiscovered Crude Oil Resources in the Lower-38 Offshore, report prepared for the U.S. DOE/Office of Fossil Energy, June 1988, pg. 38.

06P00084 
discoveries will be in smaller fields, and would be most impacted by the incremental compllance costs imposed by the proposed regulations.

\section{Lease Bonus and Geological and Geophysical Cost Assumptions.}

In the ERG analysis, the lease price paid for each model project was estimated as a function of four factors: the average price per tract, the exploratory success rate (exploratory dry holes drilled per successful exploratory well), the ratio of expected production (more commonly referred to as the finding rate), and the number of platforms per discovery well. Geological and geophysical costs were determined as a fraction of estimated lease costs.

Lease costs used in the economic analysis of the model projects were determined based on the prices paid on tracts in 1986 Gulf of Mexico lease sales. Lease costs in other regions were based on the 1986 Gulf of Mexico prices paid, but were adjusted according to lease costs paid in Gulf of Mexico sales in the years corresponding to the last lease sales held in the other regions (1983 for the Atlantic and 1984 for the Pacific and Alaska). For example, lease costs for tracts in the Pacific were determined by using the average price for a tract in the Gulf of Mexico in 1986, divided by the average price per tract in the Gulf in 1984. The logic for this approach is that the Gulf, being a mature producing region, is more representative of true market lease values, where prices will rise and fall according to market conditions. Prices paid in the Gulf were considered to be representative of prices paid in other regions.

This approach is flawed for several reasons. First, lease costs in a region other than the Gulf are not necessarily related to historical Gulf Coast lease costs. The costs in other regions do not take into account the considerably different risks, costs, and infrastructure existing in these regions, relative to those associated with the Gulf. Because of the considerably higher costs and risks associated with development in areas other 
than the Gulf, lease costs would be lower, all other things being equal, to account for the added costs and risks.

Second, the approach used for estimating lease costs is based on the economic conditions in 1986, a low point in terms of the economic conditions and forecasts influencing offshore development (with oil prices at $\$ 14$ to $\$ 15$ per barrel). In reality, lease costs are determined as a function of the estimated future value of the potential resource. This valuation would depend on the size of the potential resource, the probability of successful discovery, and forecast future prices. Lease costs, therefore should account for changes in anticipated future prices. In ERG's analysis, different lease costs should have been used for each of the price tracks considered.

Finally, ERG's estimate of geological and geophysical (G\&G) costs was determined as a percentage of the lease bid. Based on data for offshore expenditures in the Lower-48 reported by the Department of Commerce and the American Petroleum Institute, ERG acknowledges that this percentage has ranged from $6.5 \%$ in 1980 , to $16.3 \%$ in 1984 , to $110.5 \%$ in 1986 . The 1986 value was used in their analysis.

There are two fundamental errors associated with this methodology for determining G\&G costs. First, as discussed above, the methodology for estimating lease costs is flawed. Second and more importantly, Gor costs correspond to the technologies and procedures for performing geological and geophysical analyses, which are, on a per well basis, relatively independent of anticipated prospect value. Lease costs, on the other hand, are completely dependent on future prospect value, and are therefore primarily a function of forecast oil and gas prices. Therefore, it is unreasonable to relate these two cost components that are based on fundamentally different economic criteria.

ERG's examination of the historic relationship between G\&G and lease bonus expenditures verifies this claim. In 1980, when oil price forecasts and corresponding anticipated prospect values were high, the percentage of G\&G expenditures to lease expenditures was low (6.5\%). In contrast, in 1986, when 
oil prices had dropped to very low values and future prices were pessimistically low, the ratio of G\&G expenditures to lease expenditures was very high ( $110.5 \%)$, reflecting a pessimistic outlook for the future. Therefore, the examination of historical G\&G lease costs should have concluded that no direct relationship exists between these two cost components.

\section{High Pacific Decline Rates}

The ERG economic analysis of the model projects in the offshore Pacific assumed a $33 \%$ per year exponential decline rate for all oil producing wells in this region. This decline rate is high for the reservoir properties characteristic of the Pacific.

To examine ERG assumptions, well production data were obtained for a number of wells in representative offshore Pacific oil fields. These data were obtained from the well production data base available through Petroleum Information Services (PI). The fields selected were the same as those used by ERG to develop their values for peak production rates in the Pacific (Beta, Hondo, Hueneme, and Santa Clara fields). In addition, well production data from the Dos Cuadras field were also examined. Only wells that had actually begun to decline were considered (for example, the wells in the Hondo field have not yet started their cecline.)

The production characteristics of these selected offshore Pacific oil wells are shown in Table 2. The estimated exponential production rates were determined using decline curve software provided by PI. As shown, no wells are producing at a decline rate near $33 \%$ per year. On average, the decline race was about $15 \%$ per year, similar to that assumed for the Gulf and Atlantic regions. 


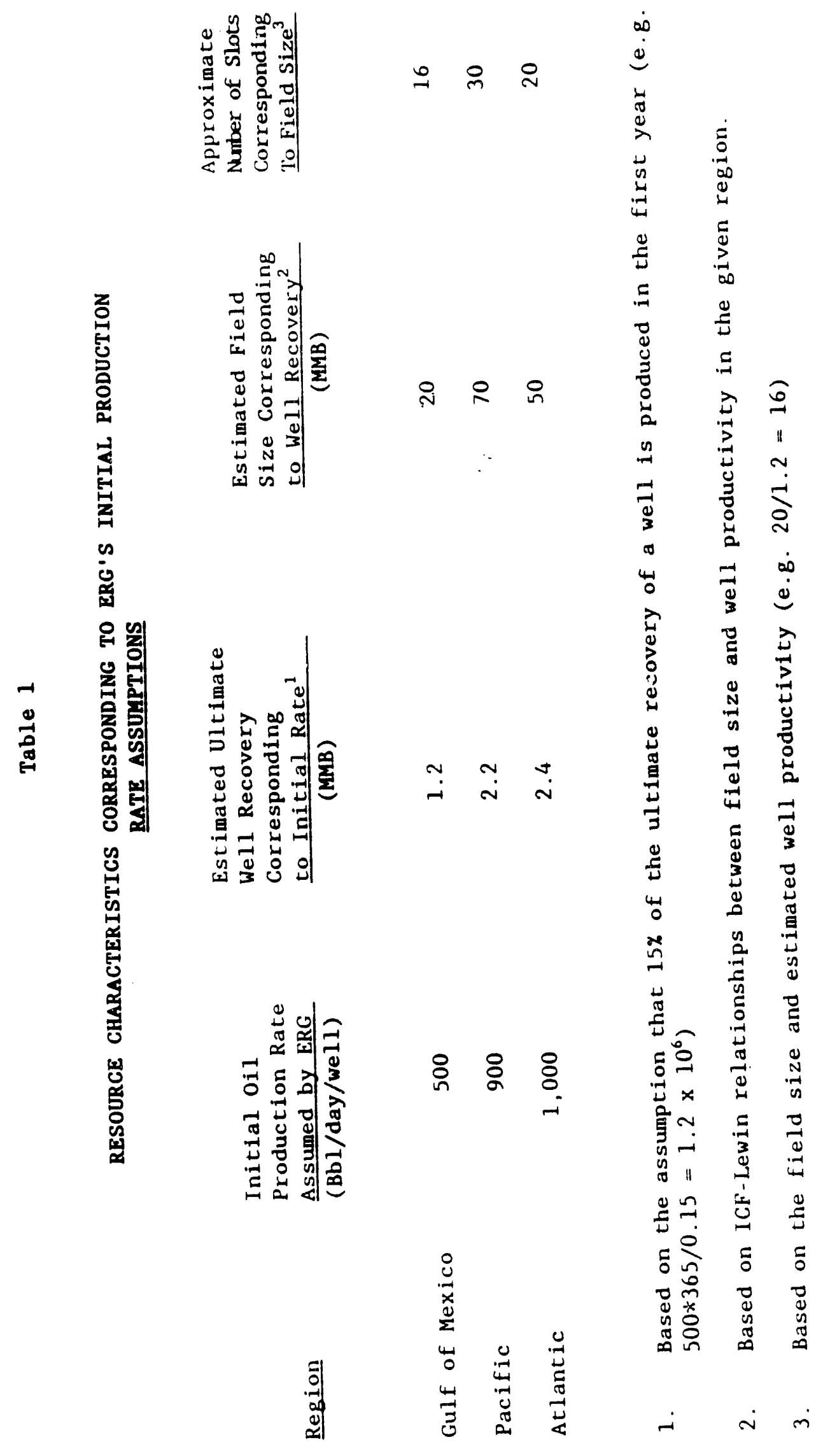


Table 2

\section{PRODUCTION CHARACTERISTICS OF SELECTED \\ PACIFIC OFFSHORE OIL WELLS}

\begin{tabular}{|c|c|c|}
\hline Field & $\begin{array}{l}\text { Approximate } \\
\text { Initial } \\
\text { Production Rate } \\
\text { (Bbl/day/well) }\end{array}$ & $\begin{array}{l}\text { Estimated } \\
\text { Exponential } \\
\frac{\text { Decline Rate }}{(\% / \mathrm{yr})}\end{array}$ \\
\hline Beta & $\begin{array}{l}296 \\
291\end{array}$ & $\begin{array}{l}14.8 \\
14.1\end{array}$ \\
\hline Santa Clara & $\begin{array}{l}371 \\
445 \\
157 \\
171\end{array}$ & $\begin{array}{l}16.2 \\
17.2 \\
17.1 \\
16.3\end{array}$ \\
\hline Hueneme & $\begin{array}{l}947 \\
499 \\
700\end{array}$ & $\begin{array}{l}15.5 \\
21.3 \\
13.2\end{array}$ \\
\hline Dos Cuadras & $\begin{array}{r}418 \\
389 \\
491 \\
235 \\
350 \\
1,198 \\
960 \\
720 \\
545 \\
752\end{array}$ & $\begin{array}{r}12.5 \\
15.2 \\
9.2 \\
16.1 \\
5.2 \\
17.3 \\
21.3 \\
16.3 \\
16.3 \\
18.6\end{array}$ \\
\hline $\mathbf{A v}$ & 522 & 15.5 \\
\hline
\end{tabular}

1. Determined by dividing the initial monthly production rate in the PI database by 30 .

2. Determined using decline curve software provided by PI. 

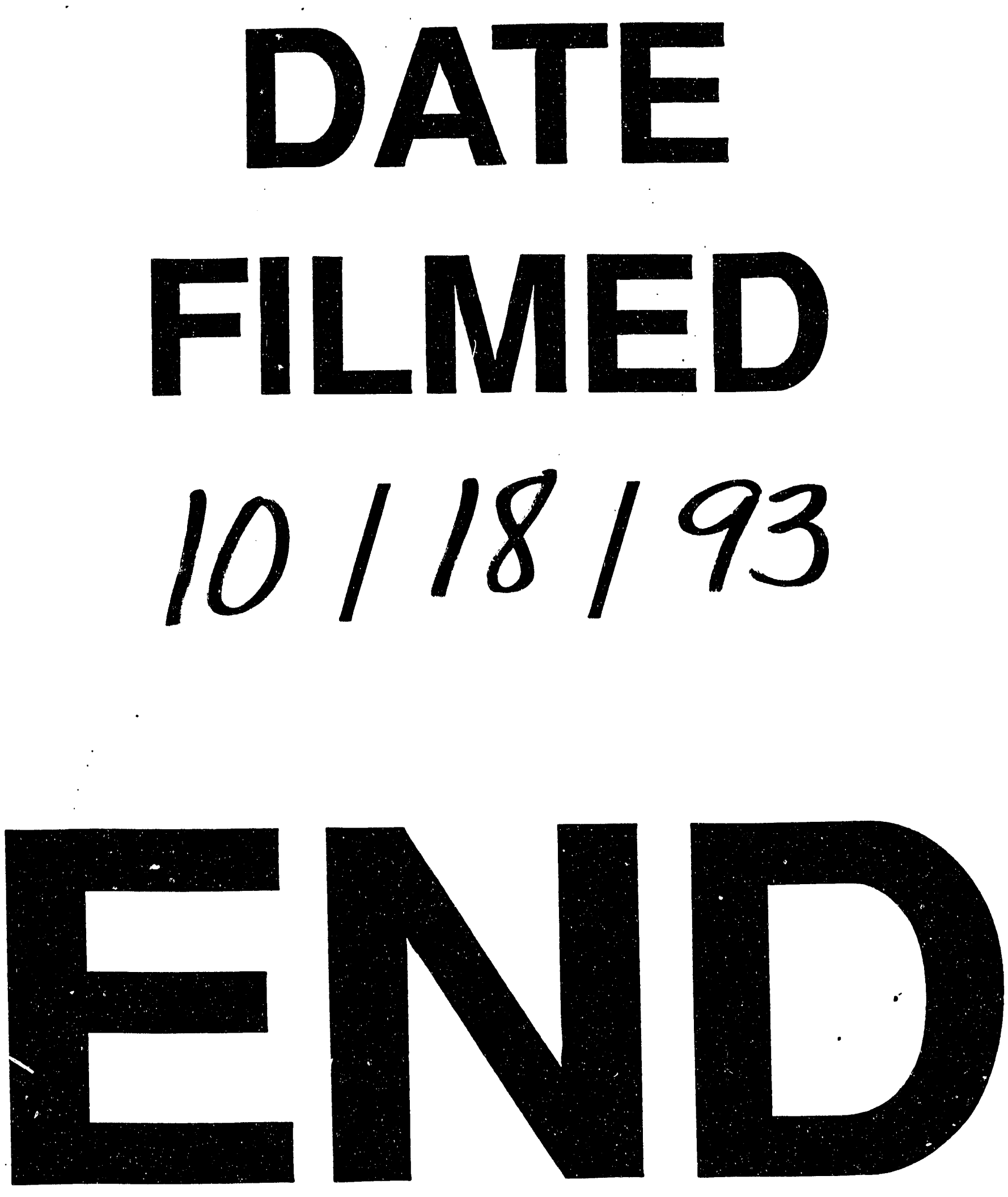